Article

\title{
The Effects of a Cold Disinfestation on Bactrocera dorsalis Survival and Navel Orange Quality
}

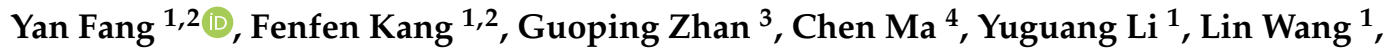 \\ Yadong Wei ${ }^{2}$, Xiwu Gao ${ }^{1}$, Zhihong $\mathrm{Li}^{1}$ and Yuejin Wang ${ }^{1,3, *}$ \\ 1 Department of Entomology, College of Plant Protection, China Agricultural University, Beijing 100193, \\ China; yanfang_926@163.com (Y.F.); kangfenfen@customs.gov.cn (F.K.); lyg727493751@163.com (Y.L.); \\ SY20183192482@cau.edu.cn (L.W.); gaoxiwu@263.net.cn (X.G.); lizh@cau.edu.cn (Z.L.) \\ 2 The Animal, Plant \& Foodstuff Inspection Center, Tianjin Customs, Tianjin 300461, China; \\ weiyadong@customs.gov.cn \\ 3 Chinese Academy of Inspection and Quarantine, Beijing 100123, China; gp136@126.com \\ 4 National Agro-Tech Extension and Service Center, Beijing 100125, China; macfov@hotmail.com \\ * Correspondence: wangyj@caiq.org.cn; Tel.: +86-010-62841330
}

Received: 6 November 2019; Accepted: 12 December 2019; Published: 13 December 2019

\begin{abstract}
Citrus sinensis (L.) Osbeck is an important economic product in South China, but the presence of quarantine pests in this product proposes the potential threat to international trade security. To find a proper phytosanitary cold treatment for Bactrocera dorsalis (Hendel) (Diptera: Tephritidae), commonly called oriental fruit fly, one of the most serious quarantine insects in navel orange, eggs in petri dish and larvae in navel orange fruits were exposed to a $1.7^{\circ} \mathrm{C}$ cold chamber for $0-11$ days to compare the tolerance to cold treatment. The 2 nd instar larva ( 4 days) is the most tolerant stage, and the estimated time for $99.9968 \%$ mortality at the $95 \%$ confidence level is $11.3(9.5$, 14.6) days. Then 15 days was selected as the target time for the confirmatory tests, resulting in no survivors from 37,792 treated larvae with the efficacy of $99.9921 \%$ mortality at the $95 \%$ confidence level. The quality assessments were conducted to compare the effect on the navel orange fruit between cold treatment and the conventional cold storage. Results indicated that the cold treatment did not negatively affect the fruit quality. Therefore, this cold treatment showed potential as a commercial quarantine treatment for navel orange in international trade.
\end{abstract}

Keywords: Bactrocera dorsalis; navel orange; ecofriendly pest management; mortality; fruit quality

\section{Introduction}

The oriental fruit fly, Bactrocera dorsalis (Hendel), is one of the world's most damaging pests and causes trade restrictions on fresh fruits [1-3]. This pest has previously been recorded to have a wide range of hosts with more than 400 plant species in a list published by the United States Department of Agriculture-Animal and Plant Health Inspection Service (USDA-APHIS) [4]. B. dorsalis is a highly invasive species and is an important quarantine pest in Asia and Pacific Plant Protection Commission (APPPC), European Plant Protection Organization (EPPO), Caribbean Plant Protection Commission (CPPC), Comité de Sanidad Vegetal del Cono Sur (COSAV), Inter-African Phytosanitary Council (IAPSC), and Organismo Internacional Regional de Sanidad Agropecuaria (OIRSA). As of now, the fruit fly has been reported in at least 65 countries, including most of Asia, much of sub-Saharan Africa, parts of America, Oceania, and Europe [5-8]. The navel orange ("Gannan" variety), Citrus sinensis (L.) Osbeck, is famous worldwide for its high quality. In 2018, the navel orange industry achieved a total output value of nearly 2 billion dollars in China and outside markets, employed 1 million rural labor 
workers on 104,000 ha that produced 1,170,000 tons [9]. Unfortunately, B. dorsalis is a potential pest in the navel orange, threatening the safety of the navel orange export [5].

The risk of introducing exotic pests into new areas is rising in the wake of the increasing agricultural trade, and the development of postharvest treatment to control insects in commodities can improve the quarantine security and expedite new trade in agricultural products. The main pest management approaches for eliminating exotic insects from a commodity are applied broadly as chemical and physical treatments. These include fumigants, temperature treatments (heat and cold), irradiation, controlled atmospheres, and combinations of these [10]. Methyl bromide fumigation is the most common approach for controlling exotic pests but is expected to be replaced by physical treatments because of methyl bromide depleting the ozone layer [10]. Physical treatments are typically applied to fresh fruits because these commodities are infested by internally feeding pests, such as tephritid fruit flies, and cold treatment is an effective measure in cold-tolerant commodities [11,12]. The pupa and adult stages of tephritid fruit flies may hardly be found in infested fruit, and phytosanitary treatments target the egg and larval stages for disinfestation [13].

Research studies have demonstrated that cold disinfestation is an effective approach in controlling Bactrocera zonata (Saunders) in orange [14,15]; Bactrocera invadens (Drew, Tsuruta, and White) (synonym of B. dorsalis) in orange, and "Hass" avocado [15-17]; Zeugodacus cucurbitae (Coquillett) (former Bactrocera cucurtitae (Coquillett)) in navel orange [13]; Bactrocera tryoni (Froggatt) in lemon, orange, mandarin, and blueberry [18-20]; Ceratitis capitata (Wiedemann) in kiwifruit, litchi, lemon, orange, mandarin, grape, pepper, "Hass" avocado, and navel orange [13,20-26]; Ceratitis rosa (Karsch) in "Hass" avocado [26]; Ceratitis cosyra (Walker) in "Hass" avocado [26]; Phthorimaea operculella (Zeller) in potato [27]; and Pseudococcus affinis (Maskell) on Royal Gala Apple [28]. The effective lethal time value for cold disinfestation was dependent on the type of insect and fruit [29]. Furthermore, earlier researches have compared the difference of the tolerance to cold treatment between fruit flies [13,30,31]. Until now, many cold treatment standards have been widely used internationally [32,33].

Traditionally, a treatment protocol should provide quarantine security for a pest with minimal impact on commodity quality $[10,34]$. An integrated quarantine treatment first with exposure to $1.5^{\circ} \mathrm{C}$ for 3 days and second with exposure to a controlled atmosphere at $25^{\circ} \mathrm{C}$ could complete insect mortality with no negative effects on the quality of "Clemenules" mandarins [35]. Hofman et al. reported that an integrated treatment with hot water of $41^{\circ} \mathrm{C}$ for $25-30 \mathrm{~min}$, or $42{ }^{\circ} \mathrm{C}$ for $25 \mathrm{~min}$ following 16 days at $1{ }^{\circ} \mathrm{C}$, could improve the external and internal fruit quality of avocado and control fruit flies [36]. Other data showed that $6{ }^{\circ} \mathrm{C}$ for 3 days, followed by $1{ }^{\circ} \mathrm{C}$ for 16 days, improves ripe "Hass" avocado fruit quality, with no negative effects, while also providing B. tryoni disinfestation efficacy [37]. Among the treatments accepted for quarantine measures, cold disinfestation is an effective approach in controlling pests that are present in fresh fruits [32,33]. However, the treatment also needs to meet the requirements for minimal impact on commodity quality.

The objective of this study was to compare the cold tolerance of the different life stages of $B$. dorsalis that infest navel orange and determine the minimum number of days of cold treatment that provides quarantine security with no negative effects on navel orange quality.

\section{Materials and Methods}

\subsection{Test Insects}

The original population of $B$. dorsalis that was used in this experiment was collected from wax apple in Chongzuo, China, in 2017 and 2018. This species is maintained at the Chinese Academy of Inspection and Quarantine in Beijing, China, and reared on a standard diet modified from Liu et al. [38]. This fruit fly colony has been maintained for nearly 1 year with the occasional inclusion of wild flies. 


\subsection{Fruit Infestation}

The navel oranges, ("Gannan" variety) originating from the Gannan area, were sourced from Jinyuanbao Binhai agricultural product transaction market in Tianjin, China, and were stored at $4.0^{\circ} \mathrm{C}$. The fruits did not receive direct pesticide applications and were free from pesticide residues. To reduce contamination with microorganisms, the fruits (mean weight $=0.22 \pm 0.03 \mathrm{~kg}$ ) were washed with dishwashing liquid, rinsed with water, and then allowed to air dry at ambient temperature.

The navel orange is an attractive host for $B$. dorsalis, and larvae were obtained by puncturing fruits with pins and exposing them to adults in screen cages $(120$ by 60 by $60 \mathrm{~cm})$ for oviposition. The age and number of the adult flies in each cage could influence the number of eggs in each fruit. On each of the infestation, 63 fruits were placed in a cage which contains about 8000 adults (rate of male/female is nearly 1:1). The infestation was conducted 15-30 days after adult emergence and infested 3-5 times in one batch of the colony. To obtain an infestation rate of $>50$ larvae per fruit, each fruit was punctured approximately 50 times to a depth of $1-2 \mathrm{~cm}$ and was exposed to fruit flies in the cages for $2-4 \mathrm{~h}$. Eggs in fruits were incubated at $26 \pm 0.5{ }^{\circ} \mathrm{C}$ for 2,4 , and 6 days to obtain the 1st, 2nd, and 3rd instars, respectively. In the egg trial, eggs were collected from egging bottles, then pipetted onto pieces of black cotton cloth and placed in a $0.1 \mathrm{~m}$ petri dish with moderate distilled water and 3 drops of sugar water for hatching in the experiments. Each petri dish contained 200 eggs.

\subsection{Development of B. dorsalis in the Navel Orange}

Navel oranges infested with fruit fly were stored to $26 \pm 0.5{ }^{\circ} \mathrm{C}$ and $65 \% \pm 5 \% \mathrm{RH}$ for various periods. In this study, we controlled development time to affect their capacity to develop into the different larval stages. To obtain enough larvae, fruits were exposed to fruit flies in the cages for approximately $2 \mathrm{~h}$. Fruits in ventilated plastic cages were placed in a climate chamber (KBF 720, BINDER Inc, Tuttlingen, Germany) with a stated accuracy of $0.5^{\circ} \mathrm{C}$. At days $2,4,6,8$, and 9, approximately 100 larvae in 2-3 fruits infested with $B$. dorsalis were randomly selected and immediately examined with a dissecting microscope for them in each treatment. According to the identification from Zhou et al., the stages of $B$. dorsalis larvae were recorded [39].

\subsection{Effect of Cold Disinfestation on B. dorsalis Survival}

Different larval stages of $B$. dorsalis in the navel oranges were exposed to the cold chamber for various periods to examine the effect of cold disinfestation on pest survival. Fruits infested with B. dorsalis were placed on a rectangular plastic basket and loaded into a chamber (HRT-105P, Chong Qing Well Co, Chongqing, China) with an accuracy of $1.7^{\circ} \mathrm{C} \pm 0.3^{\circ} \mathrm{C}$ for cold treatment. Before each trial, the thermoprobes were calibrated by a calibrator (RTC-156 B, Ametek Co., Alleroed, Denmark). Each test read 10 times, and the average result for each thermoprobe was used for correction purposes. During the experiment, thermoprobes (Testo 177-T4, Testo SE \& Co. KGaA, Lenzkirch, Germany) with an accuracy of $\pm 0.2{ }^{\circ} \mathrm{C}$ were placed at a diagonal in the core of the largest fruit in the environmental chamber, and six temperatures of the chamber and the center of fruit were recorded every $30 \mathrm{~min}$.

In the egg treatment, the petri dish temperatures were consistent with the chamber air temperature, and the treatment was deemed to have started immediately after the chamber air temperature reached the target treatment temperature. Larvae treatment was deemed to have started immediately after all the centers of the fruits had reached the target temperature. In this study, the center temperature of the fruits required about $4 \mathrm{~h}$ to reach the target temperature. On days $0,1,3,5,7,9$, and 11 , petri dishes loaded with eggs and fruits infested with $B$. dorsalis were randomly selected, removed from the cold chamber, and examined for mortality after 5 days and 2 days recovery in the $26.0^{\circ} \mathrm{C}$ chamber. Three replicates were used in the larval trial and four in the egg trial. Eggs that were hatching were counted as live, and larvae that did not move were scored as dead. Larvae movement or not was determined by placing the unmoving larvae on a napkin. 


\subsection{Confirmatory Tests}

Based on the results of the effect of cold disinfestation on survival to determine which life stage of B. dorsalis was the most cold-tolerant, a large-scale disinfestation trial was undertaken over the most cold-tolerant life stage of this pest. On each of the confirmatory tests, 54 navel oranges were placed in the cage for oviposition. Approximately $90 \%$ of the fruits infested with B. dorsalis were placed into a $1.7^{\circ} \mathrm{C}$ cold chamber $(70$ by 80 by $90 \mathrm{~cm}$ ), and the remaining infested fruits were used as the control. During the confirmatory tests, thermoprobes were placed at a diagonal in the core of the largest fruit in the cold chamber. Treatment was deemed to have begun, and mortality of larvae was determined as above.

\subsection{Fruit Quality Assessment}

Navel orange fruits were used for the assessment of the internal and external qualities at cold treatment $\left(1.7^{\circ} \mathrm{C}\right)$ and the conventional cold storage $\left(4^{\circ} \mathrm{C}\right)$. The changes in fruit quality were compared between cold treatment and cold storage. In the case of cold treatment, the fruit quality was determined on the fruits after exposure to $1.7^{\circ} \mathrm{C}$ for 0,8 , and 15 days, followed by a 7 day cold storage period at $4{ }^{\circ} \mathrm{C}$. In the case of cold storage treatments, the fruit quality was determined for the fruits after the exposure to $4.0^{\circ} \mathrm{C}$ for $0,8,15$, and 22 days. The following quality attributes were determined: peel color, fruit firmness, vitamin C (Vc), soluble solids concentration (SSC), and titratable acidity (TA).

\subsubsection{Peel Color}

The peel color was determined by Hunter Lab parameters with a colorimeter (Chroma meter CR-400, Konica Minolta sensing Inc., Tokyo, Japan). A specific color index (CI) for citrus was calculated as $\mathrm{CI}=1000 \times \mathrm{a} /(\mathrm{L} \times \mathrm{b})[40]$. For each treatment, 36 fruits were measured three times each, along the equatorial region of each fruit.

\subsubsection{Fruit Firmness}

The firmness of 36 fruits was evaluated by using a penetrometer (Fruit pressure tester FT327, TR Ltd., Forli, Italy) equipped with a $3 \mathrm{~mm}$ diameter probe and operated at a constant penetration speed, with each fruit being measured 3 times along the equatorial region.

\subsubsection{Vitamin C}

For each treatment, vitamin $\mathrm{C}(\mathrm{Vc})$ was extracted from fresh navel orange flesh using oxalates and then filtered for use. Three measures of vitamin $C$ were determined in 9 different fruits per treatment. Vitamin $C$ was quantified by titration with 26 -dichlorophenol indophenol, and the results were recorded as grams of vitamin $C$ per kilogram of navel orange flesh.

\subsubsection{Soluble Solids Concentration}

The soluble solids concentration (SSC) was determined by using a digital refractometer (RX-5000 $\alpha$, ATAGO Co. LTD., Tokyo, Japan) at $20^{\circ} \mathrm{C}$ and expressed as a percentage. For each treatment, 12 fruits comprising 6 replications were squeezed to obtain juice.

\subsubsection{Titratable Acidity}

For the experiments, the titratable acidity (TA) was determined by titration with $0.1 \mathrm{~mol} / \mathrm{L} \mathrm{NaOH}$ with a $1 \%$ phenolphthalein indicator $(\% \mathrm{w} / \mathrm{v})$, and the results were recorded as a percentage $(\%$ $\mathrm{w} / \mathrm{w})$. For each treatment, the juice was obtained from 9 fruits, and each measurement comprised three replications. 


\subsection{Statistical Analysis}

To make comparisons among the cold tolerance of the different life stages, time-response data on the mortality were arcsine transformed to improve normality and subjected to analysis of covariance (ANCOVA) by using the General Linear Model (GLM) (version 17, SPSS Inc., Chicago, IL, USA). For each replicate, the mortality values were adjusted for control mortality calculated using Abbott's formula [41]. Probit and logit analysis (LeOra Software, Berkeley, CA, USA) were performed on the time-response data for all days for B. dorsalis to calculate the predicted times to $99 \%\left(\mathrm{LT}_{99}\right)$ and $99.9968 \%$ ( $\left.\mathrm{LT}_{99.9968}\right)$ mortality. For the confirmatory test, the mortality proportion $(1-P u)$ associated with treating a number of $B$. dorsalis with zero survivors was calculated by the following equation:

$$
1-P u=(1-C)^{1 / n}
$$

where $C$ is the confidence level, and $\mathrm{n}$ is the number of insects treated with no survivor [42].

To determine the effect of cold treatment and cold storage on fruit quality, two-way analysis of variance and Tukey's multiple comparison tests were applied with the SPSS software package.

\section{Results}

\subsection{Development of B. Dorsalis in Navel Orange}

Before the trial, the development of $B$. dorsalis larvae in navel orange was observed, Figure 1. For B. dorsalis in navel orange, the percentage of larval development was $92 \%$ at the 1 st instar on day 2, $90 \%$ at the 2 nd instar on day 4 , and $94 \%$ at the 3rd instar on day 6 . On days 8 and 9 , all of the species tested were able to develop to 3rd instar. Therefore, we considered 2 day-old, 4 day-old, and 6 day-old larvae of this species as the 1st, 2nd, and 3rd instar, respectively.



Figure 1. Percentage of different larval stages of Bactrocera dorsalis in navel orange ( $\square$, First instar; $\square$, Second instar; $₫$, Third instar).

\subsection{Effect of Cold Disinfestation on B. Dorsalis Survival}

The mortality increased with increasing treatment time for all life stages, no eggs hatched $\geq 7$ days, and no larvae survived $\geq 9$ days, Table 1 . Result showed no significant effect of the interaction between treatment days and stages $\left(F_{2,30}=1.897 ; p=0.168\right)$ on the survival; whereas a significant impact was found for the treatment days $\left(F_{1,32}=242.260 ; p<0.001\right)$ and life stages $\left(F_{2,32}=8.451 ; p=0.001\right)$. The mortality of 1st and 2nd instar larvae was significantly lower than the mortality of the 3rd instar and eggs. However, no significant difference was observed between the 1st and 2nd instar larvae. In addition, the mortality of 2 nd instar was lower than that of the 1 st instar at 1, 3, 5, and 7 days, Table 1.

The parameters from the results of the probit analysis (probit and logit model), including slope and estimated day to $99 \%\left(\mathrm{LT}_{99}\right)$ and $99.9968 \%$ ( $\left.\mathrm{LT}_{99.9968}\right)$ mortality, are presented in Table 2. The 
estimated $\mathrm{LT}_{99}$ was very close to the day that produced $100 \%$ mortality in the cold treatment, Tables 1 and 2, and the $\mathrm{LT}_{99}$ of the 2nd instar was higher than that for the other stage, indicating that the resistance of 2nd instar was higher. Furthermore, the LT $_{99.9968}$ of the 2nd instar was highest in all tested stages. Thus, the 2nd instar larvae likely to be found in fruits were determined to be the most tolerant stage in the navel orange.

Table 1. Mortality (mean \pm SE) of Bactrocera dorsalis subjected to cold treatment at $1.7^{\circ} \mathrm{C}$ in navel oranges.

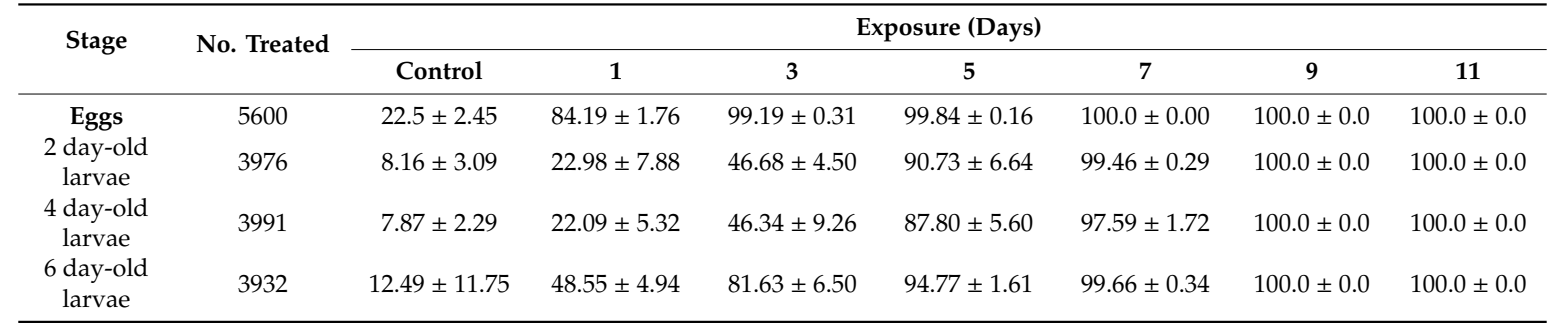

Table 2. Probit and logit analysis of Bactrocera dorsalis mortality response to cold treatment at $1.7^{\circ} \mathrm{C}$.

\begin{tabular}{ccccc}
\hline Analyzing Model & Stage & Slope \pm SE & LT $_{\mathbf{9 9}}$ (95\% CL) (Days) & LT $_{\mathbf{9 9 . 9 9 6 8}}$ (95\% CL) (Days) \\
\hline \multirow{3}{*}{ Probit } & Eggs & $0.62 \pm 0.07$ & $3.1(2.6,4.3)$ & $5.8(4.5,8.6)$ \\
& 2 day-old larvae & $0.58 \pm 0.03$ & $7.1(6.2,8.8)$ & $10.0(8.4,12.9)$ \\
& 4 day-old larvae & $0.47 \pm 0.02$ & $7.8(6.7,9.6)$ & $11.3(9.5,14.6)$ \\
& 6 day-old larvae & $0.41 \pm 0.02$ & $6.4(5.7,7.3)$ & $10.5(9.2,12.3)$ \\
\hline \multirow{2}{*}{ Logit } & Eggs & $1.45 \pm 0.19$ & $3.0(2.6,3.6)$ & $7.0(5.8,8.9)$ \\
& 2 day-old larvae & $1.07 \pm 0.08$ & $7.5(6.3,10.3)$ & $12.9(10.1,19.6)$ \\
& 4 day-old larvae & $0.82 \pm 0.04$ & $8.4(6.9,11.7)$ & $15.4(12.0,23.3)$ \\
& 6 day-old larvae & $0.78 \pm 0.04$ & $6.8(5.9,8.1)$ & $14.2(12.0,17.7)$ \\
\hline
\end{tabular}

\subsection{Confirmatory Tests}

Confirmatory tests were conducted to validate the estimated day to achieve $99.9968 \%$ mortality in B. dorsalis 2 nd instar, and 15 days was selected as the target day according to the estimates of probit and logit analysis, Table 2.

No survivors were found in the 15 -day treatment at $1.7^{\circ} \mathrm{C}$, and the data are presented in Table 3, whereas the percentage of survivors in the control was $94.09 \%$. In this study, calculating the disinfestation efficacy $(1-P u)$ with a confidence level of $95 \%$ by the equation is $99.9916 \%$.

Table 3. Results of large-scale tests on second instar Bactrocera dorsalis larvae in navel oranges for 15 days at $1.7^{\circ} \mathrm{C}$.

\begin{tabular}{cccc}
\hline \multirow{2}{*}{ Trial No. } & \multicolumn{3}{c}{ Treated } \\
\cline { 2 - 4 } & No. of Fruit Infested & No. of Insects Treated & No. of Surviving Individuals \\
\hline Control & 18 & 4724 & 4445 \\
1 & 48 & 13,136 & 0 \\
2 & 48 & 8784 & 0 \\
3 & 48 & 15,872 & 0 \\
& Total & 37,792 & 0 \\
\hline
\end{tabular}

\subsection{Quality of Navel Orange Exposed to Cold Treatment}

Comparisons of the effect of storage time and temperatures at $1.7^{\circ} \mathrm{C}$ and $4.0^{\circ} \mathrm{C}$ on the objective attributes of navel orange are presented in Figure 2a-e. The results showed no significant effect of the interaction between temperatures and storage time for peel color $\left(F_{3,856}=1.721, p=0.161\right)$ Figure 2a and firmness $\left(F_{3,856}=0.836, p=0.474\right)$ Figure $2 b$, whereas a significant impact was found for the $\operatorname{SSC}\left(F_{3,40}=3.852, p=0.016\right)$ Figure $2 \mathrm{c}$, TA $\left(F_{3,16}=4.263, p=0.022\right)$ Figure $2 \mathrm{~d}$, and $\mathrm{Vc}_{\mathrm{c}}\left(F_{3,16}=7.707\right.$, $p=0.002)$ Figure 2e. 
When the effect of storage time on the quality of the navel orange was measured, a significant impact was observed on the firmness $\left(F_{3,856}=5.743, p=0.001\right)$ Figure $2 b, \operatorname{SSC}\left(F_{3,40}=45.659, p<0.001\right)$ Figure $2 c$, TA $\left(F_{3,16}=87.157, p<0.001\right)$ Figure $2 d$, and $V_{c}\left(F_{3,16}=119.006, p<0.001\right)$ Figure 2e, whereas no significant impact was observed on the peel color $\left(F_{3,856}=0.984 p=0.400\right)$ Figure $2 \mathrm{a}$. The result indicated that the quality of the navel orange was affected by the storage time.

No significant difference between temperatures was observed on the firmness $\left(F_{1,856}=0.041\right.$, $p=0.839)$ Figure $2 b, \operatorname{SSC}\left(F_{1,40}=3.517, p=0.068\right)$ Figure $2 c$, and TA $\left(F_{1,16}=0.531, p=0.477\right)$ Figure $2 d$, whereas a significant impact was observed on the peel color $\left(F_{1,856}=9.999, p=0.002\right)$ Figure $2 \mathrm{a}$ and $V_{c}$ $\left(F_{1,16}=14.593, p=0.002\right)$ Figure $2 \mathrm{e}$. In addition, the values of $\mathrm{CI}$ and $\mathrm{Vc}$ of the navel orange changed slower in the cold treatment Figure $2 \mathrm{a}$,e.
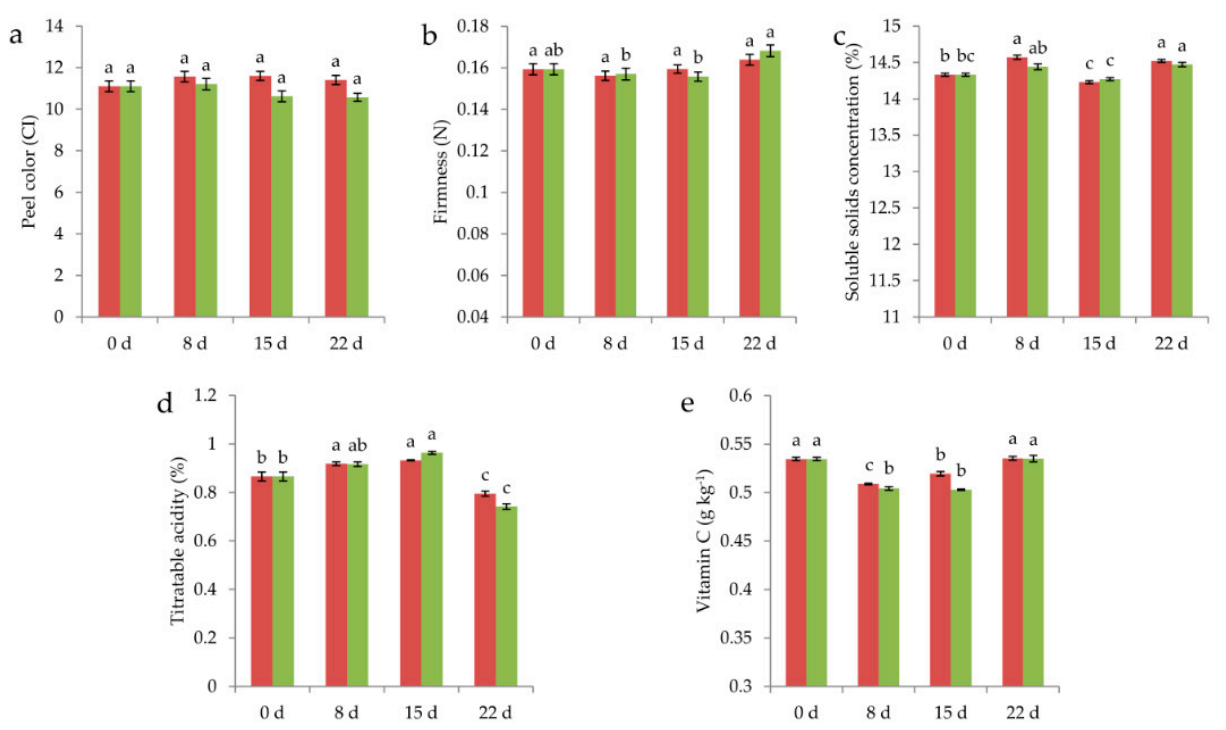

Figure 2. Changes in quality of navel orange, peel color (a), firmness (b), soluble solids concentration (c), titratable acidity $(\mathbf{d})$ and vitamin $\mathrm{C}(\mathbf{e})$, through time after storage at $1.7^{\circ} \mathrm{C}$ and $4.0^{\circ} \mathrm{C}\left(\square, 1.7^{\circ} \mathrm{C}\right.$; $\left.\square, 4.0^{\circ} \mathrm{C}\right)$. Data are the means $\pm \mathrm{SE}$. Values with different letters on each bar in the two groups differ significantly $(p<5 \%)$.

\section{Discussion}

In the present study, $B$. dorsalis 2 nd instar larvae appear to be the most cold-tolerant life stages tested at $1.7^{\circ} \mathrm{C}$. Therefore, large-scale confirmatory testing for a cold disinfestation treatment targeted the 2nd instar larvae. In the confirmatory test, no survivors were found after the 15 days treatment at $1.7^{\circ} \mathrm{C}$, resulting in a disinfestation efficacy of $99.9916 \%$ at the $95 \%$ confidence level. The results suggest that holding the fruit center temperature at $\leq 1.7^{\circ} \mathrm{C}$ for a minimum of 15 days is an effective treatment for the control of $B$. dorsalis in the navel orange.

The fruit type may affect the cold treatment period required for disinfestation. Fruit type could affect the development of fruit flies, which in turn affects the cold tolerance of fruit flies. Generally, individuals of a certain age in days are considered as the 1st, 2nd, and 3rd instars in a cold treatment study $[17,26,31,43]$. In this study, the percentage of larvae was $1 \%$ at 1 st instar, $90 \%$ at 2 nd instar, and $9 \%$ at 3 rd instar on day 4 , and the result was consistent with the research in oranges and "Hass" avocado [16,17]. The relationship between the percentages of the different stages and cold tolerance is not clear. Therefore, further experiments are needed to confirm the effect of the proportions of 1 st, 2 nd, and 3rd instars on pest cold tolerance.

The infestation method may also affect the cold treatment period required for disinfestation. Commonly, a natural infestation method and an artificial infestation method are the two main types of infection methods $[13,15]$. In artificially infested fruit, eggs are placed near the fruit center but are laid near the fruit surface in naturally infested fruit. The fruit center is the warmest place during 
the treatment, differences in the infestation methods may have an influence on the response to the cold treatment. In addition, the temperature, most tolerant life stage, colony source, and the identified endpoint were considered the factors that affect the cold treatment period required for disinfestation [13].

Usually, an effective cold treatment protocol should meet the demand to kill the pest and minimize the negative effects on host quality at the same time $[10,29,34]$. The present results confirm that cold treatment did not negatively affect fruit quality. In summary, the present results support the implementation of cold phytosanitary treatment at $1.7^{\circ} \mathrm{C}$ for 15 days for the navel orange.

\section{Conclusions}

This study has documented the effect of cold phytosanitary treatment on B. dorsalis mortality and postharvest quality of navel orange at low temperatures. The results confirmed that 15 days at $1.7^{\circ} \mathrm{C}$ could provide quarantine security for controlling B. dorsalis at an efficacy level of $99.9916 \%$. Moreover, cold treatment did not negatively affect fruit quality. Therefore, this cold treatment showed potential as a commercial quarantine treatment for navel orange in international trade.

Author Contributions: Conceptualization, Y.F., F.K., G.Z., X.G., Z.L., and Y.W.; Data curation, Y.F., Y.L., and L.W.; Formal analysis, Y.F., G.Z., and C.M.; Funding acquisition, Y.F., F.K., and Y.W.; Methodology, Y.F., F.K., G.Z., and Y.W.; Project administration, Y.F., F.K., and Y.W.; Software, Y.F. and C.M.; Supervision, Y.F., F.K., and Y.W.; Validation, Y.F. and C.M.; Writing-Original draft, Y.F., C.M., Y.L., and L.W.; Writing-Review and editing, Y.F., F.K., G.Z., C.M., Y.W., X.G., Z.L., and Y.W.

Funding: This research was funded by the Key Research Program of International Collaboration between China and Czech Republic (No. 2018YFE0108700) and the Research Program of the former General Administration of Quality Supervision, Inspection and Quarantine of the People's Republic of China (No. 2017IK226).

Acknowledgments: We thank L.R., B.L., P.S., L.J., J.W., and Z.Z. for technical assistance. We are grateful to the anonymous reviewers for their review of the manuscript.

Conflicts of Interest: The authors declare no conflict of interest.

\section{References}

1. Dohino, T.; Mizuno, T.; Mizuniwa, S.; Yoneda, M.; Miyazaki, I. Heat and cold tolerance of various aged eggs of Bactrocera dorsalis and B. cucurbitae (Diptera Tephritidae). Res. Bull. Pl. Prot. Japan 2014, 50, 63-69.

2. Dohino, T.; Hallman, G.J.; Grout, T.G.; Clarke, A.R.; Follett, P.A.; Cugala, D.R.; Minh Tu, D.; Murdita, W.; Hernandez, E.; Pereira, R.; et al. Phytosanitary treatments against bactrocera dorsalis (diptera: Tephritidae): Current situation and future prospects. J. Econ. Entomol. 2016, 110, 67-79.

3. Schutze, M.K.; Krosch, M.N.; Armstrong, K.F.; Chapman, T.A.; Englezou, A.; Chomič, A.; Cameron, S.L.; Hailstones, D.; Clarke, A.R. Population structure of Bactrocera dorsalis s.s., B. papayae and B. philippinensis (Diptera: Tephritidae) in southeast Asia: Evidence for a single species hypothesis using mitochondrial DNA and wing-shape data. BMC Evol. Biol. 2012, 12, 1471-1481. [CrossRef] [PubMed]

4. U.S. Department of Agriculture, Animal and Plant Health Inspection Service. Oriental Fruit Fly, Bactrocera Dorsalis, Host List. Available online: https://www.aphis.usda.gov/plant_health/plant_pest_info/fruit_flies/ downloads/host-lists/off-hostlist.pdf (accessed on 12 January 2019).

5. Crop Protection Compendium. Bactrocera dorsalis (Oriental Fruit Fly). Available online: https://www.cabi. org/ISC/datasheet/17685 (accessed on 13 January 2019).

6. Lux, S.A.; Copeland, R.S.; White, I.M.; Manrakhan, A.; Billah, M.K. A new invasive fruit fly species from the Bactrocera dorsalis (Hendel) group detected in East Africa. Insect Sci. Applic. 2003, 23, 355-361. [CrossRef]

7. Schutze, M.K.; Aketarawong, N.; Amornsak, W.; Armstrong, K.F.; Augustinos, A.A.; Barr, N.; Bo, W.; Bourtzis, K.; Boykin, L.M.; Cáceres, C.; et al. Synonymization of key pest species within the Bactrocera dorsalis species complex (Diptera: Tephritidae): Taxonomic changes based on a review of 20 years of integrative morphological, molecular, cytogenetic, behavioural and chemoecological data. Syst. Entomol. 2014, 40, 456-471. [CrossRef]

8. Nugnes, F.; Russo, E.; Viggiani, G.; Bernardo, U. First record of an invasive fruit fly belonging to Bactrocera dorsalis complex (Diptera: Tephritidae) in Europe. Insects 2018, 9, 182. [CrossRef] 
9. The People's Government of Ganzhou, China. Development of Navel Orange Industry in Southern Jiangxi. Available online: http://xxgk.ganzhou.gov.cn/c100459rf/2019-02/19/content_ 1618b1185633403bb886234569968182.shtml (accessed on 27 February 2019).

10. Follett, P.A.; Neven, L.G. Current trends in quarantine entomology. Annu. Rev. Entomol. 2006, 51, 359-385. [CrossRef]

11. Paull, R.E.; Armstrong, J.W. Insect Pests and Fresh Horticultural Products: Treatments and Responses; CABI: Wallingford, UK, 1994; p. 360.

12. Methyl Bromide Technical Options Committee. Assessment of Alternatives to Methyl Bromide; United Nations Environment Programme (UNEP): Nairobi, Kenya, 2002; pp. 231-343.

13. Follett, P.A.; Manoukis, N.C.; Mackey, B. Comparative Cold Tolerance in Ceratitis capitata and Zeugodacus cucurbitae (Diptera: Tephritidae). J. Econ. Entomol. 2018, 111, 2632-2636. [CrossRef]

14. Hallman, G.J.; Myers, S.W.; Taret, G.; Fontenot, E.A.; Vreysen, M.J.B. Phytosanitary Cold Treatment for Oranges Infested with Bactrocera zonata (Diptera: Tephritidae). J. Econ. Entomol. 2013, 106, 2336-2340. [CrossRef]

15. Hallman, G.J.; Myers, S.W.; El-Wakkad, M.F.; Tadrous, M.D.; Jessup, A.J. Development of Phytosanitary Cold Treatments for Oranges Infested with Bactrocera invadens and Bactrocera zonata (Diptera: Tephritidae) by Comparison with Existing Cold Treatment Schedules for Ceratitis capitata (Diptera: Tephritidae). J. Econ. Entomol. 2013, 106, 1608-1612. [CrossRef]

16. Grout, T.G.; Daneel, J.H.; Mohamed, S.A.; Ekesi, S.; Nderitu, P.W.; Stephen, P.R.; Hattingh, V. Cold Susceptibility and Disinfestation of Bactrocera invadens (Diptera: Tephritidae) in Oranges. J. Econ. Entomol. 2011, 104, 1180-1188. [CrossRef] [PubMed]

17. Ware, A.B.; Du Toit, C.L.N.; Mohamed, S.A.; Nderitu, P.W.; Ekasi, S. Cold Tolerance and Disinfestation of Bactrocera invadens (Diptera:Tephritidae) in 'Hass' Avocado. J. Econ. Entomol. 2012, 105, 1963-1970. [CrossRef]

18. Heather, N.W.; Whitfort, L.; Mclauchlan, R.; Kopittke, R. Cold disinfestation of Australian mandarins against Queensland fruit fly (Diptera: Tephritidae). Postharvest Biol. Technol. 1996, 8, 307-315. [CrossRef]

19. Jessup, A.J.; Sloggett, R.F.; Quinn, N.M. Quarantine Disinfestation of Blueberries Against Bactrocera tryoni (Froggatt) (Diptera: Tephritidae) by Cold Storage. J. Econ. Entomol. 1998, 91, 964-967. [CrossRef]

20. De Lima, C.P.F.; Jessup, A.J.; Cruickshank, L.; Walsh, C.J.; Mansfield, E.R. Cold disinfestation of citrus (Citrus spp.) for Mediterranean fruit fly (Ceratitis capitata) and Queensland fruit fly (Bactrocera tryoni) (Diptera: Tephritidae). N. Z. J. Crop Hort. Sci. 2007, 35, 39-50. [CrossRef]

21. De Lima, C.P.F. Disinfestation of kiwifruit using cold storage as a quarantine treatment for Mediterranean fruit fly (Ceratitis capitate Wiedemann). N. Z. J. Crop Hort. Sci. 1992, 20, 223-227. [CrossRef]

22. Ware, A.B.; Tate, B.A.; Stephen, P.R.; Daneel, J.H.; Beck, R.R. Cold disinfestation of Mediterranean (Ceratitis capitate Wiedemann) and Natal (Ceratitis rosa Karsh) fruit fly-infested litchis (Litchi chinensis Sonn.). S. Afr. Litchi Grow. Assoc. Yearb. 2004, 16, 47-51.

23. Grout, T.G.; Stephen, P.R.; Daneel, J.H.; Hattingh, V. Cold Treatment of Ceratitis capitata (Diptera: Tephritidae) in Oranges Using a Larval Endpoint. J. Econ. Entomol. 2011, 104, 1174-1179. [CrossRef]

24. De Lima, C.P.F.; Jessup, A.J.; Mansfield, E.R.; Daniels, D. Cold treatment of table grapes infested with Mediterranean fruit fly Ceratitis capitate (Wiedemann) and Queensland fruit fly B. tryoni (Froggatt) Diptera: Tephritidae. N. Z. J. Crop Hort. Sci. 2011, 39, 95-105. [CrossRef]

25. Fallik, E.; Perzelan, Y.; Alkalai-Tuvia, S.; Nemny-Lavy, E.; Nestel, D. Development of cold quarantine protocols to arrest the development of the Mediterranean fruit fly (Ceratitis capitata) in pepper (Capsicum annuum L.) fruit after harvest. Postharvest Biol. Technol. 2012, 70, 7-12. [CrossRef]

26. Ware, A.B.; du Toit, C.L.N. Cold Disinfestation of "Hass" Avocado (Persia americana) of Three Species of Fruit Fly (Diptera: Tephritidae)-Ceratitis capitata, Ceratitis rosa, and Ceratitis cosyra. J. Econ. Entomol. 2017, 110, 954-960. [CrossRef] [PubMed]

27. Saour, G.; Al-Daoude, A.; Ismail, H. Evaluation of potato tuber moth mortality following postharvest cold storage of potatoes. Crop Prot. 2012, 38, 44-48. [CrossRef]

28. Hoy, L.E.; Whiting, D.C. Low-Temperature Storage as a Postharvest Treatment To Control Pseudococcus affinis (Homoptera: Pseudococcidae) on Royal Gala Apples. J. Econ. Entomol. 1997, 90, 1377-1381. [CrossRef]

29. Ben-Amor, R.; Dhouibi, M.H.; Aguayo, E. Hot water treatments combined with cold storage as a tool for Ectomyelois ceratoniae mortality and maintenance of Deglet Noor palm date quality. Postharvest Biol. Technol. 2016, 112, 247-255. [CrossRef] 
30. Hallman, G.J.; Myers, S.W.; Jessup, A.J.; Islam, A. Comparison of In Vitro Heat and Cold Tolerances of the New Invasive Species Bactrocera invadens (Diptera: Tephritidae) With Three Known Tephritids. J. Econ. Entomol. 2011, 104, 21-25. [CrossRef] [PubMed]

31. Myers, S.W.; Cancio-Martinez, E.; Hallman, G.J.; Fontenot, E.A.; Vreysen, M.J.B. Relative Tolerance of Six Bactrocera (Diptera: Tephritidae) Species to Phytosanitary Cold Treatment. J. Econ. Entomol. 2016, 109, 2341-2347. [CrossRef] [PubMed]

32. International Plant Protection Convention. Adopted International Standards for Phytosanitary Measures. Available online: https://www.ippc.int/en/core-activities/standards-setting/ispms/ (accessed on 12 February 2019).

33. U.S. Department of Agriculture, Animal and Plant Health Inspection Service. Treatment Manual. Available online: https://www.aphis.usda.gov/import_export/plants/manuals/ports/downloads/treatment. pdf (accessed on 4 March 2019).

34. Yahia, E.M. Effects of insect quarantine treatments on the quality of horticultural crops. Stewart Postharvest Rev. 2006, 2, 1-18. [CrossRef]

35. Palou, L.; Jacas, J.A.; Marcilla, A.; Alonso, M.; del Rio, M.A. Physico-chemical and sensory quality of 'Clemenules' mandarins and survival of the Mediterranean fruit fly as affected by complementary cold and carbon dioxide quarantine treatments. Postharvest Biol. Technol. 2008, 48, 443-450. [CrossRef]

36. Hofman, P.J.; Stubbings, B.A.; Adkins, M.F.; Meiburg, G.F.; Woolf, A.B. Hot water treatments improve 'Hass' avocado fruit quality after cold disinfestation. Postharvest Biol. Technol. 2002, 24, 183-192. [CrossRef]

37. Hofman, P.J.; Stubbings, B.A.; FAdkins, M.; Corcoran, R.J.; White, A.; Woolf, A.B. Low temperature conditioning before cold disinfestation improves 'Hass' avocado fruit quality. Postharvest Biol. Technol. 2003, 28, 123-133. [CrossRef]

38. Liu, B.; Li, B.; Zhan, G.; Zha, T.; Wang, Y.; Ma, C. Forced hot-air treatment against Bactrocera papayae (Diptera: Tephritidae) in papaya. Appl. Entomol. Zool. 2017, 52, 531-541. [CrossRef]

39. Zhou, X.; Li, B.; Liu, B.; Wang, Y.; Ye, B. Preliminary investigation on the identification of the larval stages of the Bactrocera dorsalis Hendel (Chinese). Plant Quar. 2017, 31, 17-22.

40. Jiménez-Cuesta, M.; Cuquerella, J.; Martínez-Jávega, J.M. Determination of a color index for citrus fruit degreening. Proc. Int. Soc. Citric. 1981, 2, 750-753.

41. Abbott, W.S. A method of computing the effectiveness of an insecticide. J. Econ. Entomol. 1925, 18, $265-267$. [CrossRef]

42. Couey, H.M.; Chew, V. Confidence Limits and Sample Size in Quarantine Research. J. Econ. Entomol. 1986, 79, 887-890. [CrossRef]

43. Liu, T.; Li, L.; Zhang, F.; Gong, S.; Li, T.; Zhan, G.; Wang, Y. Effect of Low-Temperature Phosphine Fumigation on the Survival of Bactrocera correcta (Diptera: Tephritidae). J. Econ. Entomol. 2015, 108, 1624-1629. [CrossRef] 